\title{
Application of FRA to Improve the Design and Maintenance of Wireless Power Transfer Systems
}

\author{
Dowon Kim ${ }^{\circledR}$, A. Abu-Siada ${ }^{\circledR}$, Senior Member, IEEE, and Adrian T. Sutinjo, Senior Member, IEEE
}

\begin{abstract}
Frequency response analysis (FRA) plays an important role in the assessment of the mechanical integrity and hence, reliability of high-voltage power transformers. Wireless power transfer (WPT) system introduced by Tesla a 100 years ago based on Faraday's law of electromagnetic induction is similar to a conventional power transformer. Therefore, the reliability of a large WPT system can also be evaluated using FRA measurement. When the WPT system is constructed, the electrical components and the desired transfer distance need to be ascertained accurately. Furthermore, the structure of the winding and the electrical characteristic of the components in WPT systems may vary due to aging or fault events. FRA measurement can examine the discrepancy between the WPT system parameters and the reference fingerprint data to provide cost-effective condition monitoring-based maintenance scheme for the WPT systems. This paper presents a detailed circuit analysis of a two-coil inductively coupled WPT model in different compensating topologies to accomplish efficient energy transfer. Then, FRA measurement is used to detect the variation in the amplitude and the phase angle of the developed circuit input impedance in a wide frequency range. In addition, displacements due to the placement of ferrite material and the variation of the transfer distance between the transmitter and receiver units are investigated through practical measurements.
\end{abstract}

Index Terms-Frequency response analysis (FRA), inductive power transfer (IPT), $R L C$ resonance, wireless power transfer (WPT).

\section{INTRODUCTION}

W IRELESS power transfer (WPT) is broadly adopted for charging batteries and supplying electric power to various devices [1]-[5]. Since WPT technology was introduced a century ago by Tesla who dreamed of delivering free electric energy everywhere through the earth, his idea had been frozen until the 1990s due to the lack of funds and technology supports [6], [7]. On the other side, the wireless communication technology commercialized by Garratt [8]

Manuscript received August 6, 2018; revised October 23, 2018; accepted December 4, 2018. This work was supported in part by the Australian Government Research Training Program and in part by the Curtin Postgraduate Scholarship. The Associate Editor coordinating the review process was Branislav Djokic. (Corresponding author: Dowon Kim.)

The authors are with the Electrical and Computer Engineering Department, Curtin University, Bentley, WA 6102, Australia (e-mail: dowon.kim@postgrad.curtin.edu.au; a.abusiada@curtin.edu.au; adrian. sutinjo@curtin.edu.au).

Color versions of one or more of the figures in this paper are available online at http://ieeexplore.ieee.org.

Digital Object Identifier 10.1109/TIM.2018.2889360 has been successfully developed because it requires a small amount of electric energy for transmitting the information over long distances effectively. WPT technology resurfaced with increasing demands of electric vehicles (EVs), mobile devices, and sensors. The modern design and application of the wireless charging system for EVs were presented by Green and Boys [9]. In 2007, Massachusetts Institute of Technology demonstrated a transfer of electric power of $60 \mathrm{~W}$ at a distance of $2 \mathrm{~m}$ with $15 \%$ efficiency [10]. Korea Advanced Institute of Science Technology introduced a WPT system that can send a few hundred watts over a distance of $5 \mathrm{~m}$ in 2015 [11]. The efficiency in the demonstration of Harbin Institute of Technology, Harbin, China to transmit electric power of $2.86 \mathrm{~kW}$ at $150-\mathrm{mm}$ distance reached approximately $90 \%$ [12]. WPT can be mainly categorized into near-field and far-field applications which are also called nonradiative and radiative applications, respectively. Near-field WPT can be feasible under inductive power transfer (IPT) and capacitive power transfer (CPT). Although the performance of CPT is improving fast, IPT applications are broadly adopted for high-power and midrange distance charging applications [13].

The principle of IPT is based on Faraday's law of electromagnetic induction similar to a power transformer. An IPT system is mainly composed of a transmitting (Tx) coil and a receiving $(\mathrm{Rx})$ coil representing a primary and secondary winding of a power transformer. The difference between an IPT system and a traditional power transformer is that an IPT device has compensating capacitors at the $\mathrm{Tx}$ and $\mathrm{Rx}$ sides to reduce the leakage inductance. Also, Tx and Rx coils are loosely coupled without any magnetic core. When the IPT coils are coupled at the resonance frequency, electric power can be transferred efficiently through free space [14]. The typical transfer distance, also known as an air gap, of the current WPT systems is in the range of a few millimeters to several centimeters [15]-[17]. As the public transports (e.g., high-speed train and large ferry) adopted a wireless charging application, IPT systems in megawatt range have been recently introduced as shown in Fig. 1 [18], [19]. Hence, it is expected that the size and capacity of WPT systems to increase rapidly in the very near future. To avoid the confusion of the terminology, WPT, in this paper, is used to refer to IPT.

Frequency response analysis (FRA) has been taking a significant role to detect the mechanical deformation and to certify the reliability of power transformers in the past few 


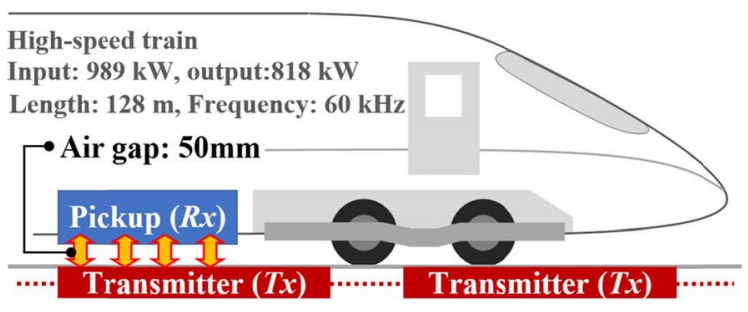

(a)

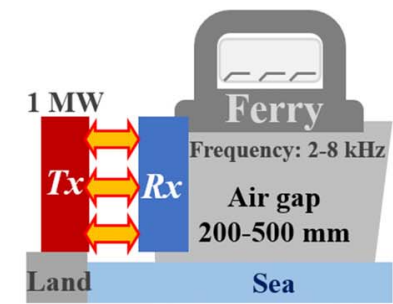

(b)

Fig. 1. Megawatt range WPT application examples. (a) High-speed train. (b) Large-scale vessel.

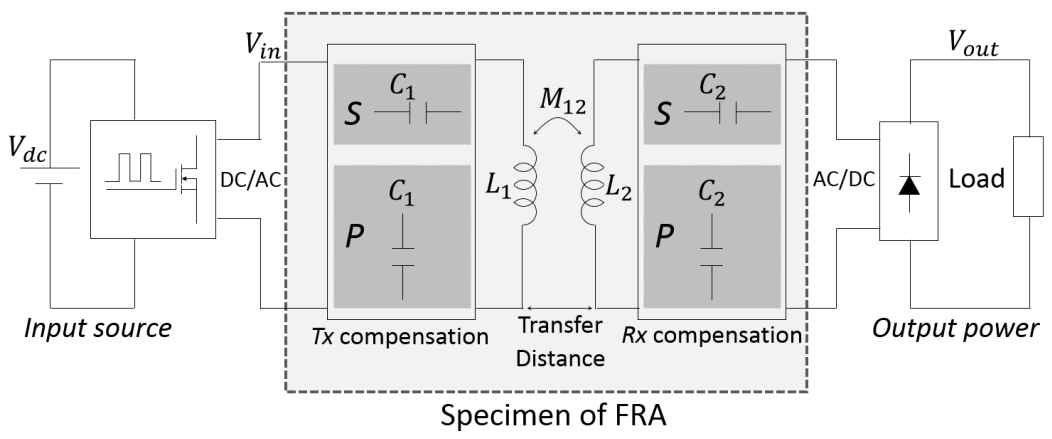

Fig. 2. Compensating scheme of inductively coupled WPT system.

decades [20]-[23]. The principle concept of FRA is based on two-port network theory [24], and it is more user-friendly, cost-effective, and robust than a vector network analyzer for the power industrial applications [25]. For the accurate verification of the WPT installation on site, and the maintenance purposes in the future, FRA can perform another critical role in the WPT industry. FRA can be adopted to clarify the characteristic of the voltage transfer ratio (VTR) and the transfer function of WPT systems [26]. In addition, the optimum distance corresponding to the maximum power transfer and the optimum resonance frequency could be correctly identified in the series-series (SS) compensation WPT system using FRA [27]. This paper introduces the characteristic of the WPT systems in various compensating topologies to mitigate the reactive component of the input impedance. To precisely tune the WPT circuit at the resonance frequency, it is important to correctly identify the compensating capacitors at the Tx and $\mathrm{Rx}$ sides. The capacitors can be connected to the Tx and Rx coils either in series or parallel, as shown in Fig. 2. Consequently, four different compensating topologies, SS, series-parallel (SP), parallel-series (PS), and parallel-parallel (PP), are basically available.

The contribution of this paper is summarized as follows.

1) Analyzing the input impedance and phase of a two-coil WPT system to tune the resonance frequency. Although the primary purpose of FRA is to assess the mechanical integrity of power transformers, the input impedance of the WPT systems can be extracted accurately using FRA measurement.

2) Presenting different patterns of the VTR over the transfer distance. When there is any variation in the air gap between the Tx and Rx coils, the performance of the
WPT system is critically affected. FRA is used to identify a precise alignment and an effective calibration.

3) Presenting the discrepancy in the FRA measurements when the magnetic coupling or the geometry of the WPT systems changes. When the WPT system is implemented on site, any mismatch between the designed parameters and the installation should be identified. In addition, it is required to monitor the changes of the electrical components of the WPT system over the time. FRA measurement is a useful application to diagnose the reliability of WPT systems.

4) Verifying the efficiency of the WPT systems based on the FRA measurements.

The rest of this paper is organized as follows.

In Section II, two-coil WPT circuit in different compensations and the equivalent input impedance are presented. Section III presents the experimental hardware setup. The practical FRA measurements on the developed WPT system at various operating conditions are presented in Section IV. The key conclusions are drawn in Section V.

\section{Circuit AnAlysis}

\section{A. Compensation Topologies}

To achieve a resonant state between the Tx and Rx coils, compensating capacitors $C_{1}$ at $\mathrm{Tx}$ side and $C_{2}$ at $\mathrm{Rx}$ side should be precisely selected and connected either in series or parallel with the coil. An SS topology is the simplest model as the resonant frequency can be easily obtained. In this topology, the value of $C_{1}$ should be maintained constant regardless of the variation in the coupling coefficient factor $k_{12}$ between the two coils and the load resistance $R_{\mathrm{L}}$. On the other hand, 


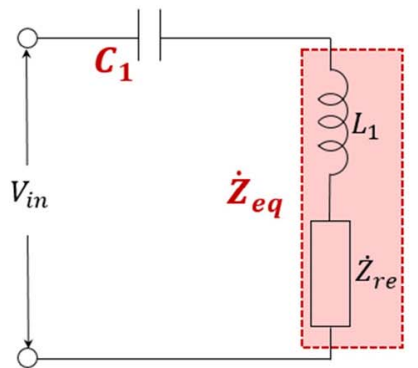

(a)

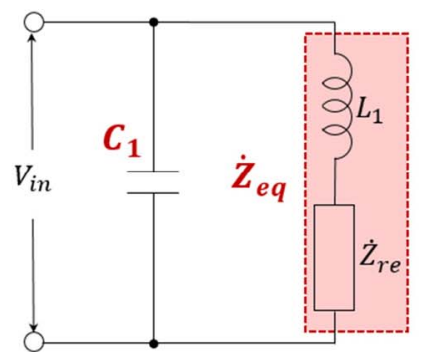

(b)

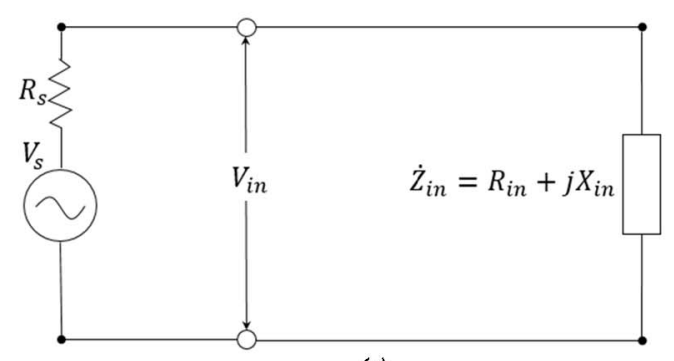

(c)

Fig. 3. Simplified IPT equivalent circuit. (a) SS or SP topology. (b) PS or PP topology. (c) Equivalent total input impedance.

TABLE I

Compensating CAPacitor Value at the Tx Side

\begin{tabular}{|c|c|c|}
\hline Model & $\omega$ & $C_{1}$ value \\
\hline$S S$ & $\omega_{o}$ & $C_{1}=1 /\left(\omega_{o}^{2} L_{1}\right)$ \\
\hline \multirow{2}{*}{$P S$} & $\omega_{0}$ & $C_{1}=\frac{L_{1}}{\left(\frac{\omega_{o}{ }^{2} k_{12} L_{1} L_{2}}{R_{L}}\right)^{2}+\left(\omega_{o} L_{1}\right)^{2}}$ \\
\hline \multirow{2}{*}{$S P$} & $\omega_{o}$ & $C_{1}=\frac{C_{2}}{\frac{L_{1}}{L_{2}}\left(1-k_{12}^{2}\right)}$ \\
\cline { 2 - 3 } & $\omega_{o}{ }^{\prime}$ & $C_{1}{ }^{\prime}=\frac{L_{2} C_{2} R_{L}^{2}}{\left(C_{2} R_{L}^{2}-L_{2}\right) L_{1}}$ \\
\hline \multirow{2}{*}{$P P$} & $\omega_{0}$ & $C_{1}=\frac{C_{2}\left(1-k_{12}^{2}\right)}{\frac{L_{1}}{L_{2}}\left\{\frac{C_{2}}{L_{2}}\left(R_{L} k_{12}{ }^{2}\right)^{2}+\left(1-k_{12}{ }^{2}\right)^{2}\right\}}$ \\
\cline { 2 - 3 } & $\omega_{o}{ }^{\prime}$ & $C_{1}{ }^{\prime}=\frac{L_{1} L_{2}^{4} C_{2}^{2}}{L_{1}^{2} L_{2}^{3} C_{2}-\frac{L_{1}^{2} L_{2}^{4}}{R_{L}^{2}}+\frac{M^{4}}{R_{L}^{2}}\left(C_{2} R_{L}{ }^{2}-L_{2}\right)^{2}}$ \\
\hline
\end{tabular}

the value of $C_{1}$ in an SP topology is affected by $k_{12}$ or $R_{\mathrm{L}}$. In PS and PP topologies, both $k_{12}$ and $R_{\mathrm{L}}$ values should be considered for the precise calculation of $C_{1}$. The value of $C_{1}$ as a function of circuit parameters in different topologies is given in Table I.

Where $\omega_{o}=1 /\left(L_{2} C_{2}\right)^{1 / 2}$ and $\omega_{o}^{\prime}=\left(\left(1 / L_{2} C_{2}\right)-\right.$ $\left.\left(1 / C_{2}^{2} R_{L}^{2}\right)\right)^{1 / 2}$ are the resonance angular frequencies in $\mathrm{rad} / \mathrm{s}$ [28], [29]. The near-field WPT system is applicable in a frequency range from tens of kilohertz to a few megahertz generally [15]. As the value of the coil interturn capacitance, generally in the range of picofarads in a high-frequency range, is much smaller than that of the value of the external compensating capacitor connected to the coil which is in the range of nanofarad to microfarad, the value of the coil interturn capacitance can be ignored [30], [31]. However, if the farfield WPT application in a frequency range from hundreds megahertz to few gigahertz is considered, or the interturn capacitor level is comparable to the compensating capacitor, the resonance frequency should be correctly tuned with the consideration of the coil self-capacitance value [32].
When the resonance frequency is $\omega_{o}^{\prime}$ (for SP and PP models), the reflected impedance $\dot{Z}_{\text {re }}$ of the equivalent circuit shown in Fig. 3(a) and (b) does not include the imaginary component from the parallel-compensated Rx side. On the other hand, both real and imaginary impedance components are reflected when $\omega_{o}$ is implemented as the resonance frequency. In this paper, the circuit analysis and the demonstrations are performed based on $\omega_{0}$. As each topology has advantages and disadvantages, the compensating circuit should be selected based on the operating frequency, load resistance, and air gap. An SS topology is preferred when the transfer distance and the load are static. PS, SP, and PP topologies need to consider various parameters to continuously tune the resonance frequency when the air gap and load are changing.

\section{B. Input Impedance}

When the resonant circuit is perfectly designed, only the real part of the input impedance is maintained as shown in Fig. 3(c).

The resistance value in different topologies discussed earlier as a function of the load resistance and mutual inductance between Rx and Tx coils $M_{12}$ is given in the following:

$$
\begin{aligned}
& \dot{Z}_{\mathrm{in}, \mathrm{SS}\left(\omega_{o}\right)}=\frac{\omega_{o}^{2} M_{12}^{2}}{R_{\mathrm{L}}} \\
& \dot{Z}_{\mathrm{in}, \mathrm{SP}\left(\omega_{o}\right)}=R_{\mathrm{L}} \frac{M_{12}^{2}}{L_{2}^{2}} \\
& \dot{Z}_{\mathrm{in}, \operatorname{PS}\left(\omega_{o}\right)}=\frac{\left(\omega_{o}^{2} M_{12}^{2}\right)^{2}+\left(\omega_{o} L_{1} R_{\mathrm{L}}\right)^{2}}{R_{\mathrm{L}}^{2} \omega_{o} L_{1}} \\
& \dot{Z}_{\mathrm{in}, \mathrm{PP}\left(\omega_{o}\right)}=\frac{\left(R_{\mathrm{L}} M_{12}^{2}\right)^{2}+\left\{\omega_{o} L_{2}\left(L_{1} L_{2}-M_{12}^{2}\right)\right\}^{2}}{R_{\mathrm{L}} M_{12}^{2} L_{2}^{2}} .
\end{aligned}
$$

The residual imaginary value of the input impedance hinders the perfect performance of WPT. The derivations of the real and imaginary values of the input impedance are provided in the Appendix. Therefore, it is important to eliminate the residual input reactance. FRA can provide a clear photograph of the impedance characteristic in various compensating topologies. As shown in Fig. $3, \dot{Z}_{\text {re }}$ represents the reflected impedance from Rx. The capacitor compensation at the Rx side can be either in series or parallel with the coil. The equivalent impedance $\dot{Z}_{\text {eq }}$ is the vector summation of $\dot{Z}_{\text {re }}$ and $X_{L_{1}}$ of the Tx coil. 

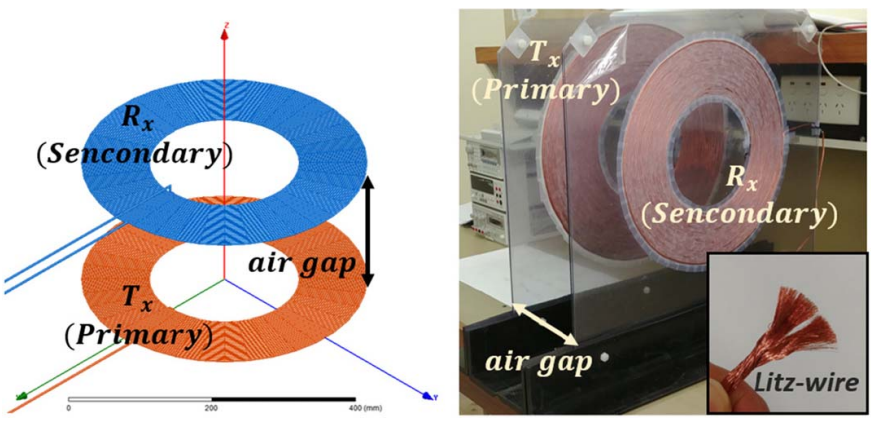

Fig. 4. Planar spiral coils design and installation.

TABLE II

PARAMETERS OF TX AND RX COILS

\begin{tabular}{|c|c|}
\hline Winding type & Planar spiral \\
\hline Wire radius & $1.5 \mathrm{~mm}$ \\
\hline Inner radius & $105 \mathrm{~mm}$ \\
\hline Number of turns & $L_{1}$ and $L_{2}: 30$ \\
\hline Spacing between turns & $0.1 \mathrm{~mm}$ \\
\hline Self-inductance & $L_{1}$ and $L_{2}: 349.3 \mu \mathrm{H}$ \\
\hline Coupling Coefficient & $10 \mathrm{~mm}$ gap: 0.8690 \\
$k_{12}$ & $55 \mathrm{~mm}$ gap: 0.4868 \\
Resonance frequency $f_{o}$ & $200 \mathrm{~mm}$ gap: 0.1126 \\
\hline$C_{2}=1 /\left(\omega_{o}^{2} L_{2}\right)$ & $20 \mathrm{kHz},\left(\omega_{0}=2 \pi f_{o}\right)$ \\
\hline
\end{tabular}

\section{Inductive Power Transfer System Design}

Planar spiral $\mathrm{Tx}$ and $\mathrm{Rx}$ coils were built to reduce the installation space as shown in Fig. 4. To investigate the variation of the coupling coefficient factor $k_{12}$ between the two coils over a varied separation distance, finite-element modeling (FEM) is conducted to calculate the parameters in Table II based on the physical dimensions provided.

The resistance of the copper wire is increased at high-frequency range due to the skin effect which affects the $Q$ factor of the circuit (ratio of the active and reactive power consumption) and reducing the overall performance of the WPT system [33]. The usage of Litz wire also known as magnet wire or superconductor can mitigate the undesirable loss at high operating frequency [34], [35]. This prototype is considered for demonstrating the wireless charging of the EV battery which calls for electric energy transfer with a relatively high-current level. Therefore, the coils in the developed WPT circuit are made of 1650 stranded Litz wire, which has 0.05mm-diameter filament (American wire gauge 44) that are independently insulated to suppress the skin and proximity effects at the high-frequency range. The ampacity of the implemented Litz wire is $20 \mathrm{~A}$ in a frequency range up to $850 \mathrm{kHz}$ [36]. As the resistance value of the wire is $6.4 \mathrm{~m} \Omega / \mathrm{m}$, the Tx (or Rx) coil of a 30-m length has 192-m $\Omega$ overall resistance. Therefore, the parasitic resistance of the winding can be ignored for the practical circuit analysis.

\section{EXPERIMENTAL FRA MEASUREMENTS AND ANALYSis}

FRA measurement is used to mainly identify three parameters: VTR, the amplitude of the transfer function, and phase

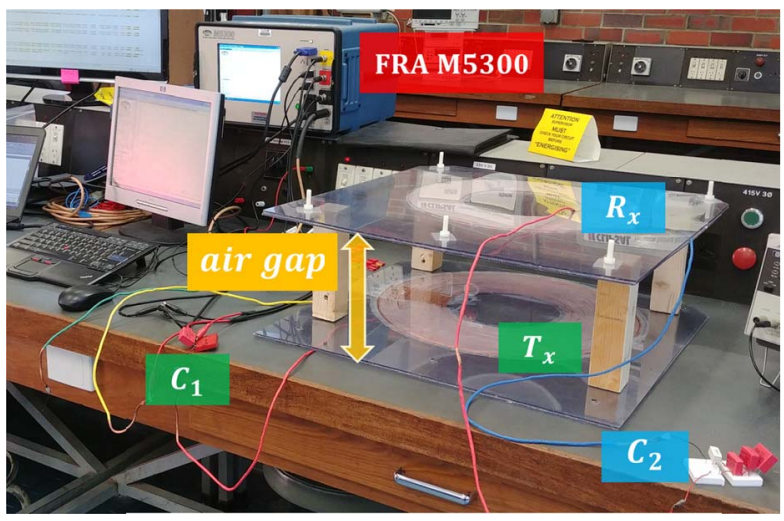

Fig. 5. Hardware setup along with theFRA.

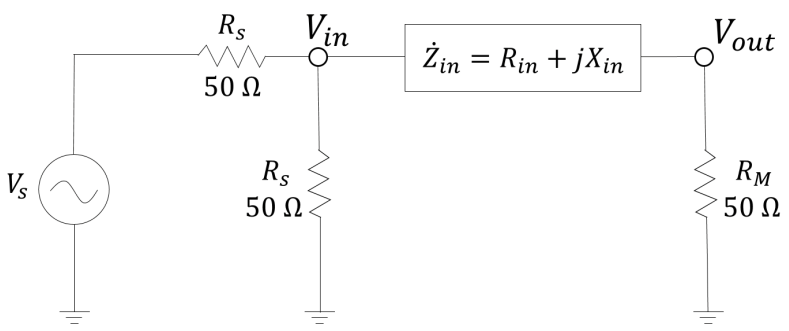

Fig. 6. FRA measurement schematic.

angle [37]. From the VTR measurement, the accurate resonant frequency can be identified. The input impedance (magnitude and angle) of the WPT system can be measured using FRA of which the characteristic of WPT system can be correctly identified with respect to the resonance frequency and the transfer distance between the two coils. A commercial FRA is used to measure the FRA characteristic of the developed WPT system shown in Fig. 5 as detailed in the following.

\section{A. Impedance Analysis}

Schematic for FRA measurement on the WPT system is depicted in Fig. 6 in which $R_{s}$ and $R_{\mathrm{M}}$ are the source and the resistance of the FRA that measures the transfer function $H_{(j \omega)}$ as in the following equations:

$$
\begin{aligned}
\mathrm{VTR} & =20 \log H_{(j \omega)}=20 \log \frac{V_{\text {out }}}{V_{\text {in }}}[\mathrm{dB}] \\
H_{(j \omega)} \angle \delta^{\circ} & =\frac{50}{Z_{\text {in }} \angle \theta^{\circ}+50}
\end{aligned}
$$

The phase angle $\delta$ of the transfer function $H_{(j \omega)}$ in (6) is a function of the input impedance and the value of $R_{\mathrm{M}}$. Therefore, the input impedance phase angle $\theta$ needs to be extracted from the obtained results to calculate the reactive component of $\dot{Z}_{\text {in }}$. The unknown real and imaginary values of $\dot{Z}_{\text {in }}$ can be acquired from (5) and (6) as follows:

$$
\begin{aligned}
& \operatorname{Re}\left(\dot{Z}_{\text {in }}\right)=\left\{\frac{50}{10^{\left(\frac{\mathrm{VTR}}{20}\right)}} \cdot \cos (-\delta)\right\}-50[\Omega] \\
& \operatorname{Im}\left(\dot{Z}_{\text {in }}\right)=\frac{50}{10^{\left(\frac{\mathrm{VTR}}{20}\right)}} \cdot \sin (-\delta)[\Omega] .
\end{aligned}
$$


TABLE III

InPut Impedance And Phase Angle Results by FRA

\begin{tabular}{|c|c|c|c|c|c|c|c|}
\hline \multicolumn{3}{|c|}{ Topologies } & \multicolumn{2}{|c|}{ Amplitude of $Z_{\text {in }}[\Omega]$} & \multicolumn{2}{|c|}{ Phase Angle $\left[{ }^{\circ}\right]$} & \multirow{2}{*}{ Tuned $C_{1}$ value } \\
\hline Gap & & $S, C_{1}$ & Calculated & Measured & Calculated & Measured & \\
\hline \multirow{2}{*}{$10 \mathrm{~mm}$} & $\mathrm{U}$ & $100 \mathrm{nF}$ & 45.74 & 47.86 & -49.61 & -50.89 & \multirow{6}{*}{$\begin{array}{l}\text { Independent } \\
\text { from } k_{12} \text { and } \\
\text { load }\end{array}$} \\
\hline & $\mathrm{T}$ & $180 \mathrm{nF}$ & 29.64 & 31.59 & 0.39 & -1.15 & \\
\hline \multirow{2}{*}{$55 \mathrm{~mm}$} & $\mathrm{U}$ & $100 \mathrm{nF}$ & 35.86 & 38.28 & -74.96 & -73.03 & \\
\hline & $\mathrm{T}$ & $180 \mathrm{nF}$ & 9.31 & 10.69 & 2.51 & -0.23 & \\
\hline $200 \mathrm{~mm}$ & $\mathrm{U}$ & $100 \mathrm{nF}$ & 34.55 & 36.24 & -89.17 & -87.27 & \\
\hline $200 \mathrm{~mm}$ & $\mathrm{~T}$ & $180 \mathrm{nF}$ & 0.70 & 1.86 & 44.86 & -11.59 & \\
\hline Gap & \multicolumn{2}{|c|}{$\boldsymbol{S P}, C_{1}$} & Calculated & Measured & Calculated & Measured & Tuned $C_{1}$ value \\
\hline \multirow{2}{*}{$10 \mathrm{~mm}$} & $\mathrm{U}$ & $180 \mathrm{nF}$ & 50.44 & 49.59 & -41.54 & -41.71 & \multirow{6}{*}{$\begin{array}{l}\text { Function of } \\
k_{12}\end{array}$} \\
\hline & $\mathrm{T}$ & $440 \mathrm{nF}$ & 38.50 & 38.35 & -11.33 & -8.02 & \\
\hline \multirow{2}{*}{$55 \mathrm{~mm}$} & $\mathrm{U}$ & $180 \mathrm{nF}$ & 15.60 & 16.65 & -40.59 & -39.39 & \\
\hline & $\mathrm{T}$ & $236 \mathrm{nF}$ & 11.85 & 13.08 & 1.16 & -2.84 & \\
\hline \multirow{2}{*}{$200 \mathrm{~mm}$} & $\mathrm{U}$ & $100 \mathrm{nF}$ & 35.12 & 36.77 & -88.97 & -87.07 & \\
\hline & $\mathrm{T}$ & $180 \mathrm{nF}$ & $\underline{\underline{0.64}}$ & $\underline{1.96}$ & -6.27 & -6.90 & \\
\hline Gap & \multicolumn{2}{|c|}{$P S, C_{1}$} & Calculated & Measured & Calculated & Measured & Tuned $C_{1}$ value \\
\hline \multirow{2}{*}{$10 \mathrm{~mm}$} & $\mathrm{U}$ & $180 \mathrm{nF}$ & 78.40 & 76.85 & -34.36 & -32.29 & \multirow{6}{*}{$\begin{array}{l}\text { Function of } \\
k_{12} \text { and load }\end{array}$} \\
\hline & $\mathrm{T}$ & $119 \mathrm{nF}$ & 94.85 & 91.58 & 2.29 & 3.39 & \\
\hline \multirow{2}{*}{$55 \mathrm{~mm}$} & $\mathrm{U}$ & $180 \mathrm{nF}$ & 212.51 & 189.82 & -14.39 & -9.83 & \\
\hline & $\mathrm{T}$ & $164 \mathrm{nF}$ & 215.59 & 198.84 & 10.68 & 7.00 & \\
\hline \multirow{2}{*}{$200 \mathrm{~mm}$} & $\mathrm{U}$ & $100 \mathrm{nF}$ & 101.09 & 100.35 & 88.53 & 84.85 & \\
\hline & $\mathrm{T}$ & $180 \mathrm{nF}$ & 2763.91 & 1026.33 & -45.50 & -13.15 & \\
\hline Gap & \multicolumn{2}{|c|}{$\boldsymbol{P P}, C_{1}$} & Calculated & Measured & Calculated & Measured & Tuned $C_{1}$ value \\
\hline \multirow{2}{*}{$10 \mathrm{~mm}$} & $\mathrm{U}$ & $180 \mathrm{nF}$ & 34.00 & 34.64 & -33.12 & -31.10 & \multirow{6}{*}{$\begin{array}{l}\text { Function of } \\
k_{12} \text { and load }\end{array}$} \\
\hline & $\mathrm{T}$ & $38 \mathrm{nF}$ & 40.47 & 39.91 & 4.50 & 6.99 & \\
\hline \multirow{2}{*}{$55 \mathrm{~mm}$} & $\mathrm{U}$ & $180 \mathrm{nF}$ & 100.14 & 94.77 & 21.19 & 20.07 & \\
\hline & $\mathrm{T}$ & $210 \mathrm{nF}$ & 107.38 & 102.10 & -1.20 & -2.52 & \\
\hline \multirow{2}{*}{$200 \mathrm{~mm}$} & $\mathrm{U}$ & $100 \mathrm{nF}$ & 98.20 & 97.50 & 88.14 & 84.68 & \\
\hline & $\mathrm{T}$ & $180 \mathrm{nF}$ & 3004.40 & 994.86 & 5.44 & 4.13 & \\
\hline
\end{tabular}

U: Untuned, T: Tuned

Consequently, the absolute value and the phase of $\dot{Z}_{\text {in }}$ can be obtained as in the following equations:

$$
\begin{aligned}
\left|\dot{Z}_{\text {in }}\right| & =\sqrt{\operatorname{Re}\left(\dot{Z}_{\text {in }}\right)^{2}+\operatorname{Im}\left(\dot{Z}_{\text {in }}\right)^{2}}[\Omega] \\
\theta & =\tan ^{-1} \frac{\operatorname{Im}\left(\dot{Z}_{\text {in }}\right)}{\operatorname{Re}\left(\dot{Z}_{\text {in }}\right)}\left[^{\circ}\right] .
\end{aligned}
$$

FRA measurements are performed on different compensations topologies of the developed WPT at various air-gap lengths between the two windings $(10,55$, and $200 \mathrm{~mm})$. For the experiments, a load resistor $R_{\mathrm{L}}$ of $50 \Omega$ was connected across the output terminals at the $\mathrm{Rx}$ side. The reference and source ports of the FRA are connected to the positive terminal of the Tx coil, while the measurement port is wired to the negative terminal of the Tx through $50-\Omega$ coaxial cables. This connection is similar to the open-circuit FRA test of a power transformer. The plots of the input impedance phase based on (10) for different compensating topologies at various air-gap lengths are shown in Fig. 7. The phase angle should be nearly zero when the compensating capacitor $C_{1}$ at the Tx side is correctly tuned. The detailed results of the measurements with a comparison to the calculated values are presented in Table III. Results show that the resonance frequency can be tuned precisely at a small air-gap distance of 10 and $55 \mathrm{~mm}$, while a significant error takes place at a distance of $200 \mathrm{~mm}$. The red trace in Fig. 7 at air-gap distance of $10 \mathrm{~mm}$ shows a smooth characteristic in the proximity of the resonance frequency of $20 \mathrm{kHz}$. It implies that the WPT system at a small transfer distance allows a wide margin to regulate the resonance condition. On the other hand, the slope of the green color plot increases significantly at $200-\mathrm{mm}$ transfer distance.

To demonstrate the performance of the untuned circuit, an arbitrary capacitor of $100 \mathrm{nF}$ at the Tx side is implemented for the SS topology. As discussed earlier, in this topology, the value of $C_{1}$ is maintained constant regardless of the change in the transfer distance. On the other hand, an arbitrary capacitor $C_{1}$ of $180 \mathrm{nF}$ at the Tx side was selected for the SP, PS, and PP topologies at air-gap distances of 10 and $55 \mathrm{~mm}$ for demonstrating the untuned condition. For both topologies, the self-inductance of the Tx coil $L_{1}$ is utilized to extract the resonance frequency $\left(\omega_{o}=1 / \sqrt{L_{1} C_{1}}\right)$ without regarding the mutual inductance variation and the load resistance. At airgap distance of $200 \mathrm{~mm}$ in the SP, PS, and PP topologies, an arbitrary capacitor of $100 \mathrm{nF}$ at the Tx side is used to observe the impedance characteristic for untuned circuit condition. At this distance, the coupling coefficient $k_{12}$ is very low (0.1126). Hence, the Tx and Rx may be considered as two decoupled coils.

An accurate frequency tuning is required to maintain zero value for the input impedance phase angle at the resonance frequency. The disagreement between the calculated and measured values increases for large air-gap distances even with the tuning of $C_{1}$ due to the rapid steep of the phase angle slope near the resonance frequency. As mentioned earlier, in the SS topology, a Tx side compensating capacitor $C_{1}$ of $100 \mathrm{nF}$ was considered to examine the untuned WPT performance. 


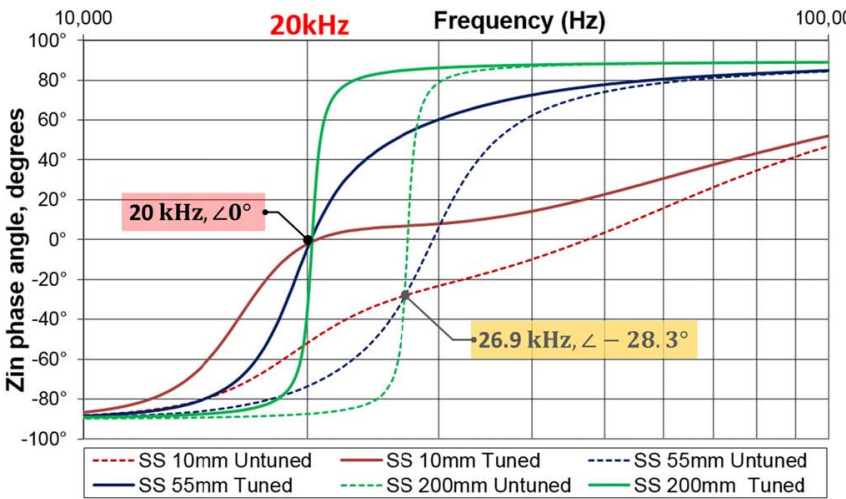

(a)

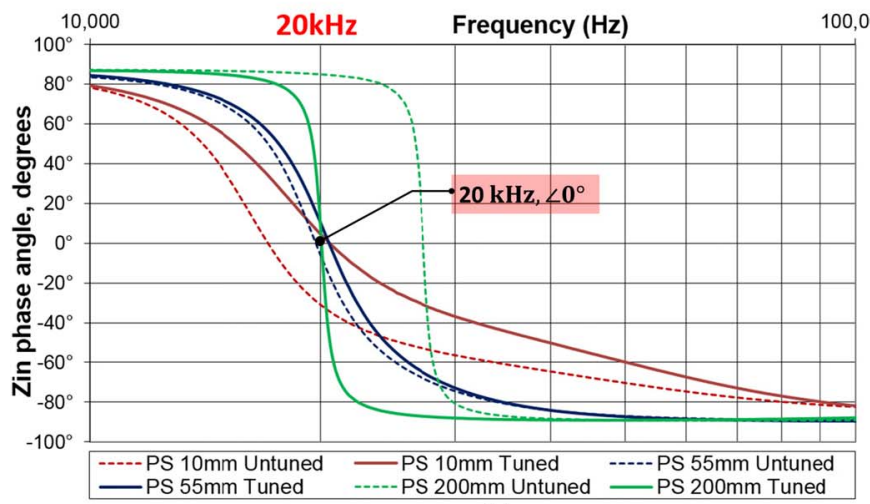

(c)

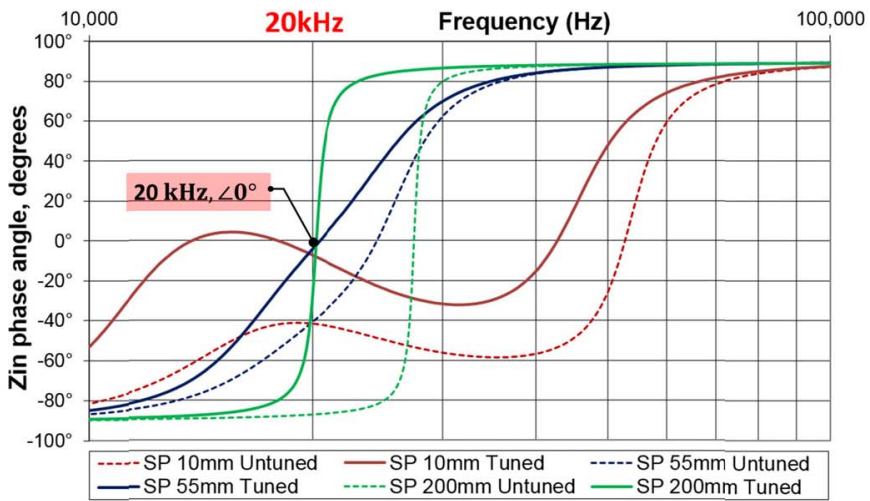

(b)

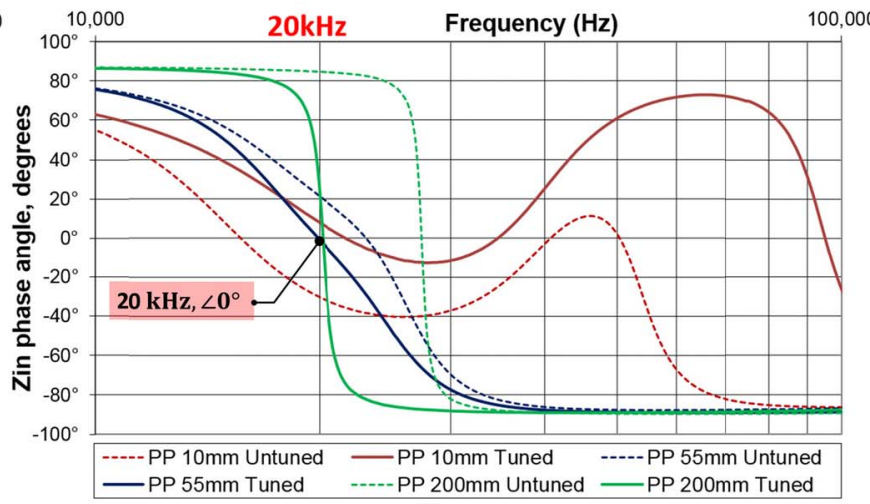

(d)

Fig. 7. Phase of the input impedance $\left(\theta^{\circ}\right)$ using FRA measurement for various compensating topologies. (a) SS topology. (b) SP topology. (c) PS topology. (d) PP topology.

If the operating frequency is set to $26.9 \mathrm{kHz}$, the phase angle will be $-28.3^{\circ}$ regardless of the transfer distance as shown in Fig. 7(a). Although the electric power can be delivered at the untuned frequency of $26.9 \mathrm{kHz}$ with a nonzero phase angle of the input impedance, it impairs the performance of the system, and it requires a large volt-ampere rating of the power supply to transfer the load demand power [38], [39]. To transfer the electric power at a frequency of $26.9-\mathrm{kHz}$ efficiently in the SS topology, the compensating capacitance $C_{2}$ in the Rx side should be changed from 180 to $100 \mathrm{nF}$, while the value of $C_{1}$ is maintained at $100 \mathrm{nF}$. The amplitude of the input impedance in the PS and PP topologies at air-gap distances of 55 and $200 \mathrm{~mm}$ is much higher than that of the input impedance in the SS and SP topologies as listed in Table III. From the comprehensive review of the results for the investigated circuits, any topology as shown in Fig. 7 is barely suitable for the WPT system at 200-mm distance.

\section{B. Voltage Transfer Ratio Patterns Over Varied Transfer Distance}

When the distance of the air gap between the Tx and Rx coils varies, the pattern of the VTR is affected due to the change in the mutual inductance between the two coils. In the SS topology, the shape of the VTR waveform in the vicinity of the resonance frequency is narrow and sharp when the transfer distance increases [27]. The VTR for SS and SP topologies gradually increases with the increase in the frequency, and it reaches a maximum level at the resonant frequency $(20 \mathrm{kHz})$ after which the VTR starts to gradually decrease as depicted in Fig. 8(a) and (b). On the other hand, the VTR for PS and PP topologies will have an opposite trend as shown in Fig. 8(c) and (d).

It is worth to note that the accurate maximum or minimum value of VTR is not observed exactly at the frequency of $20 \mathrm{kHz}$ for $10-\mathrm{mm}$ air-gap distance due to the effect of frequency bifurcation [28]. The frequency bifurcation can be identified by various parameters including self-inductance and mutual inductance of the coils, load resistance, and resonance frequency [28]. Results also show that the amplitude of the input impedance in the SS and SP topologies decreases when the air gap increases as shown in Fig. 9(a) and (b). On the contrary, the impedance level of the PS and PP system increases significantly over the distance as depicted in Fig. 9(c) and (d). The shapes of the VTR signatures shown in Fig. 8 are of the opposite trend to the impedance plots depicted in Fig. 9 because VTR and impedance level are inversely proportional based on (5) and (6). It is also clarified from the VTR and the impedance plots that a $200-\mathrm{mm}$ air gap does not provide appropriate performance regardless of the Rx compensation topology as stated in Section IV-A.

\section{LCL Topology and Ferrite Material on the Coils}

To examine the variation of the FRA results with the placement of ferrite material on the coils at a distance 

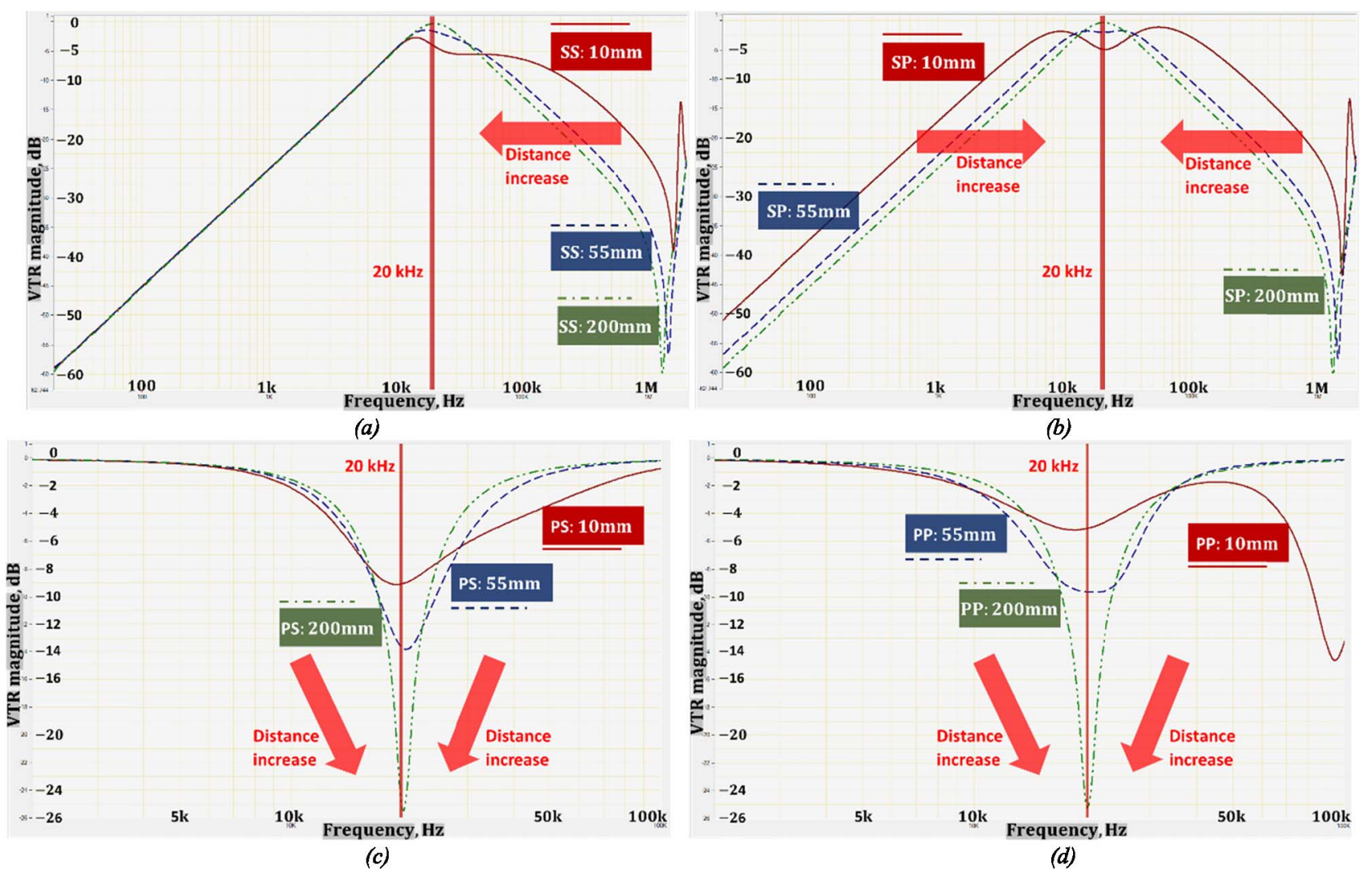

Fig. 8. VTR patterns at various transfer distances. (a) SS topology. (b) SP topology. (c) PS topology. (d) PP topology.

of $55 \mathrm{~mm}$, the PP topology was selected. For maintaining resonant condition, the PP topology requires considering more parameters than others as presented in Table I. However, it has a high input impedance with a smooth variation in the vicinity of the resonance frequency $(20 \mathrm{kHz})$ as shown in Fig. 10. Hence, the PP system provides a sufficient level of the input impedance and a broad tolerance to maintain the resonant condition.

For enhancing the power transfer rate of the WPT system, a ferrite material is implemented with the copper wire to strengthen the magnetic coupling between the coils and reduce the flux leakage path [17], [40]. For the purpose of enhancing the electrical insulation and the mechanical integrity of the system, the Tx and Rx coils are placed between two acrylic boards of $5 \mathrm{~mm}$ thickness, and the ferrite bars are positioned on the lower surface of the Tx winding acrylic board as shown in Fig. 11. The impact of the nonconductive obstruction in the air gap is insignificant, and the transfer efficiency of the WPT system with the medium between the coils is almost identical to the WPT system in the free space [41], [42].

The width, height, and length of a single ferrite bar are 10,10 , and $160 \mathrm{~mm}$, respectively. The 12 ferrite rods are positioned at an interval of $30^{\circ}$ as shown in Fig. 12(a). The coupling coefficient and the inductance values at the investigated distance are calculated using FEM as listed in Table IV. An additional inductance $L_{r}$ is connected to the Tx coil in series to achieve the resonance condition as shown in Fig. 13. Also, this coil acts as a current filter to provide a pure sinusoidal current signal to the WPT circuit [39]. The system comprising a series inductance $L_{r}$ and PP topology is known as $L C L$ resonant inverter. When the ferrite rods are moderately and significantly repositioned as shown in Fig. 12(b) and (c), respectively, the deviations of the VTR amplitude from the initial rods position at the resonance frequency $(20 \mathrm{kHz})$ and 55-mm air gap are measured using FRA as 0.114 and $0.132 \mathrm{~dB}$, respectively, as shown in Fig. 14(a). It can also be observed that the deviation in the VTR amplitude increases in the frequency range around the resonance frequency. Fig. 14(b) shows that the phase angle $\delta$ of the transfer function $H_{(j \omega)}$ at $20 \mathrm{kHz}$ is maintained at $0^{\circ}$ for the initial position of the ferrite rods as the circuit was tuned based on this position. This angle changes to $1.439^{\circ}$ and $3.902^{\circ}$ when the ferrite bars are moderately and significantly relocated, respectively.

These results validate the feasibility of FRA to precisely detect the deformation of the ferrite material in the WPT system similar to analyzing the magnetizing characteristic of the power transformer within the low-frequency range [43]. Also, the regular FRA results can indicate the deterioration trends of the resistance, inductance, and capacitance components in WPT systems over time [44]. When the WPT design is completed, the initial FRA measurement of the system can be obtained at the laboratory or the workshop. Then, the quality of the WPT installation is clarified by comparing the fingerprint to the on-site measurement data. Furthermore, the reliability of the WPT system can be assessed by benchmarking the future measurements for regular maintenance, relocation, or investigation of WPT systems as described in the flowchart of Fig. 15. 


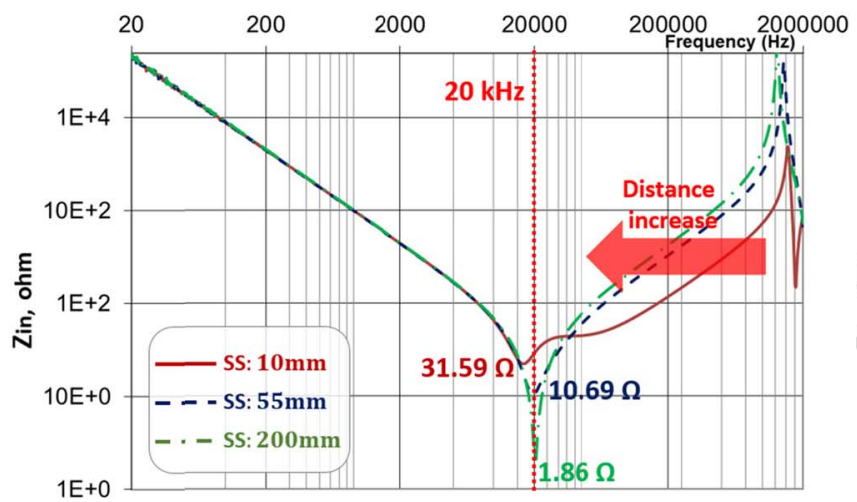

$1 \mathrm{E}+0$

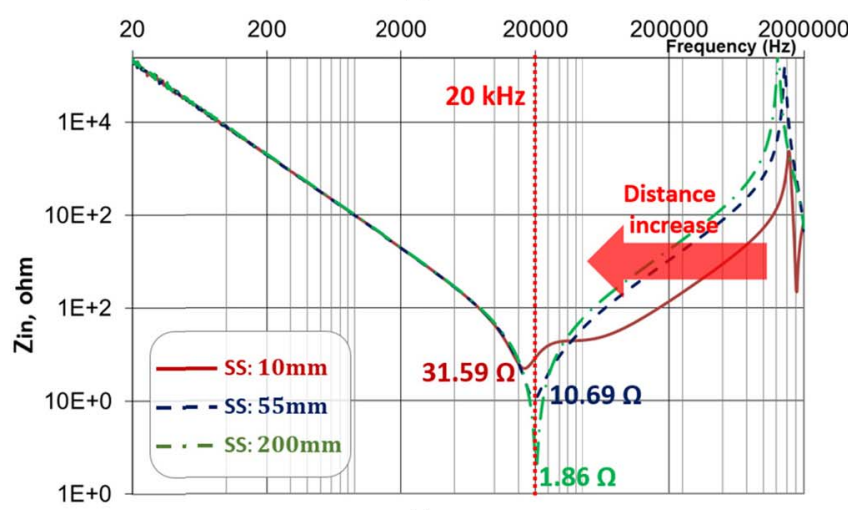

(a)

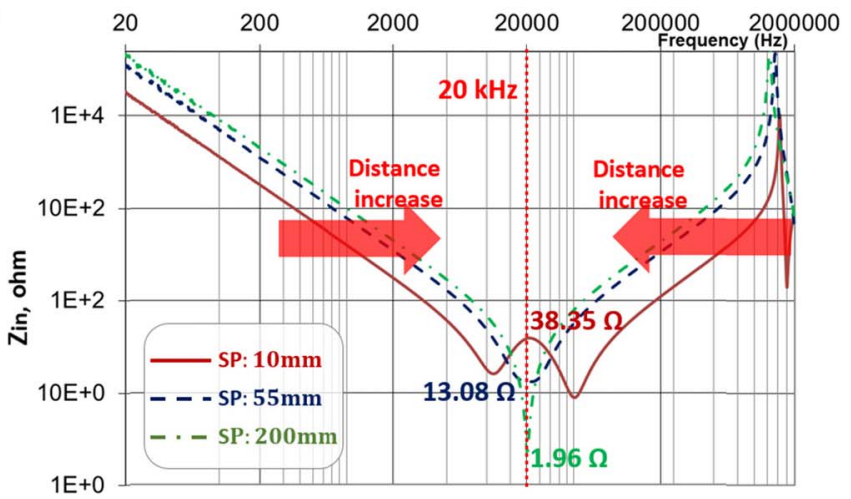

(b)

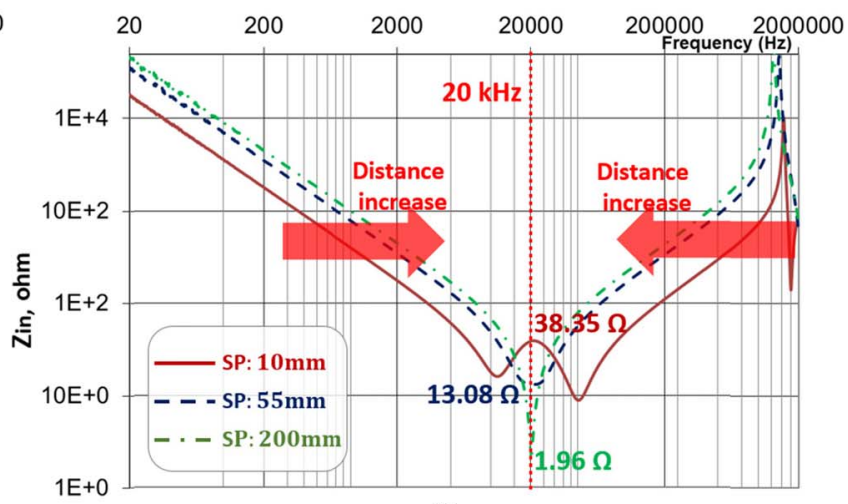

(b)

Fig. 9. Input impedance patterns at various transfer distances. (a) SS topology. (b) SP topology. (c) PS topology. (d) PP topology.

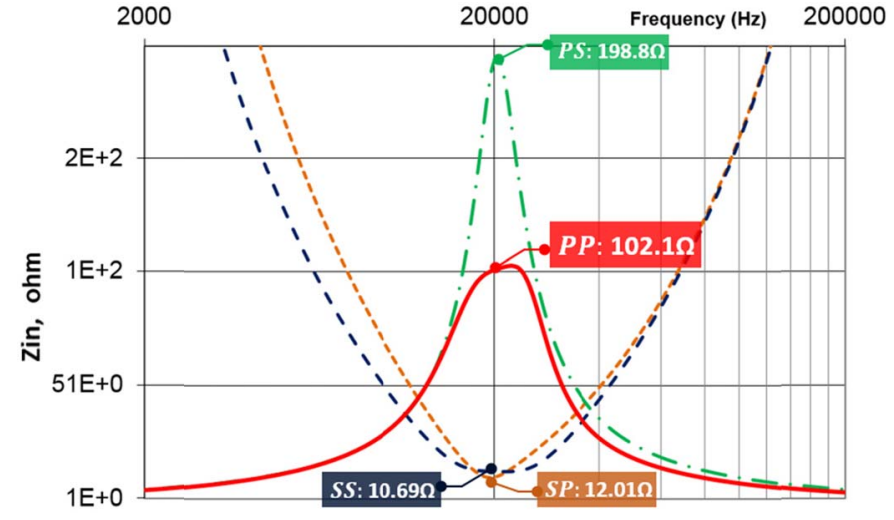

Fig. 10. Input impedance amplitude of PP topology at the air gap of $55 \mathrm{~mm}$.

\section{Practical Demonstration of WPT System and Discussion}

The efficiency of the WPT system in the PP topology with the ferrite material and the series inductance $L_{r}$ is examined on the developed WPT prototype that is shown schematically in Fig. 13. When the value of the compensating capacitors at both $\mathrm{Tx}$ and $\mathrm{Rx}$ sides are 173 and $175 \mathrm{nF}$ as presented in Table IV, the reactive component of the input impedance is not clearly eliminated, and the input impedance of the WPT prototype comprises a capacitive reactance. Therefore, $L_{r}$ of $150 \mu \mathrm{H}$ can compensate this residual capacitive reactance and helps provide a sinusoidal current to the circuit [45].
TABLE IV

Parameters of the WPT System With Ferrite Material

\begin{tabular}{|c|c|c|c|c|c|c|}
\hline Gap & $k_{12}$ & $L_{1}[\mu \mathrm{H}]$ & $C_{1}[\mathrm{nF}]$ & $L_{2}[\mu \mathrm{H}]$ & $C_{2}[\mathrm{nF}]$ & $L_{r}[\mu \mathrm{H}]$ \\
\hline $55 \mathrm{~mm}$ & 0.541 & 493.4 & 173 & 353 & 175 & 150 \\
\hline
\end{tabular}

The demonstration in this paper considers that the Tx unit is a stationary device, while the Rx unit is equipped on the mobile device. In the developed system, an overall efficiency $\eta_{o}$ achieved is $85.75 \%$ as depicted in Table V. When an input dc voltage of $30 \mathrm{~V}$ is supplied, an output ac voltage of $16.31 \mathrm{~V}$ and a current of $0.324 \mathrm{~A}$ with a phase difference of $22.19^{\circ}$ are induced across the load resistance at $20 \mathrm{kHz}$ as depicted in Fig. 16. The switching loss at the power electronic devices (i.e., insulated-gate bipolar transistors or metal-oxide semiconductor field-effect transistors) is a major cause of the low efficiency in WPT systems [45], [46]. Therefore, the recent WPT systems adopt a zero voltage switching or zero current switching (also known as soft switching) converter with complex gate-driver applications, and their efficiency reaches almost 90\% [12], [47].

While two-coil-based inductive coupling WPT is demonstrated, in this paper, FRA can also analyze the characteristic of WPT system with multiple repeaters, capacitive coupling WPT systems, and other complex topologies (e.g., double-side $L C L$ and $C C L$ ) [48]-[53]. 


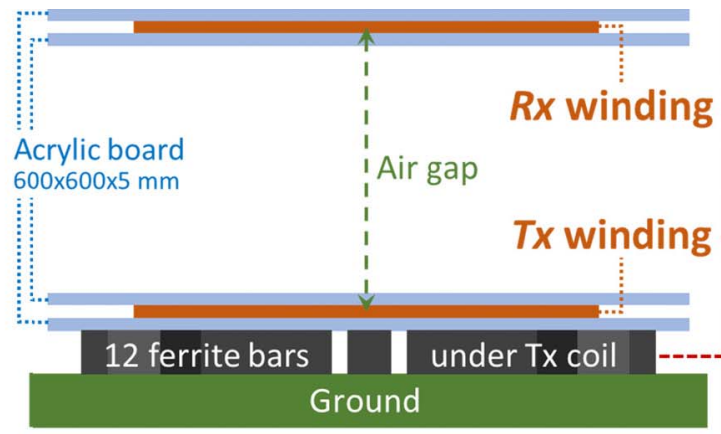

(a)

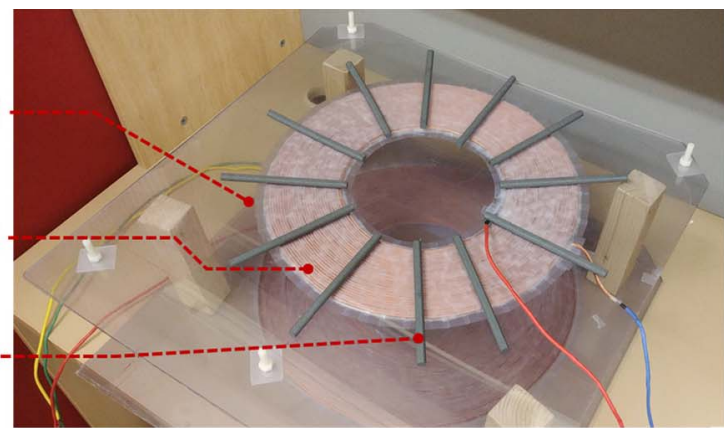

(b)

Fig. 11. Layout of the prototype WPT. (a) Cross-sectional diagram. (b) Actual implementation.

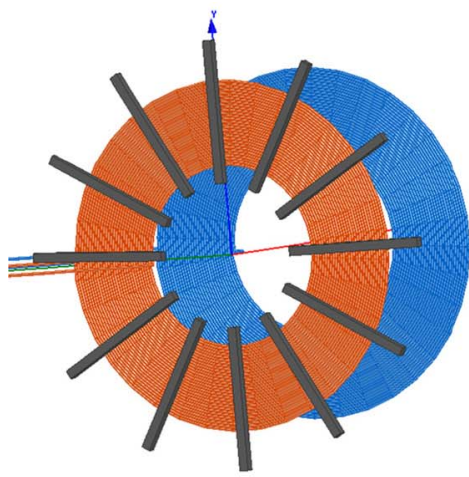

(a)

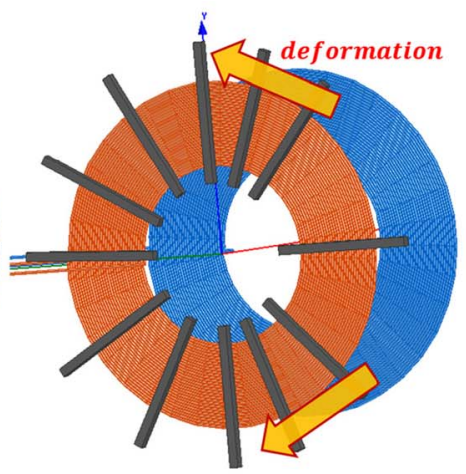

(b)

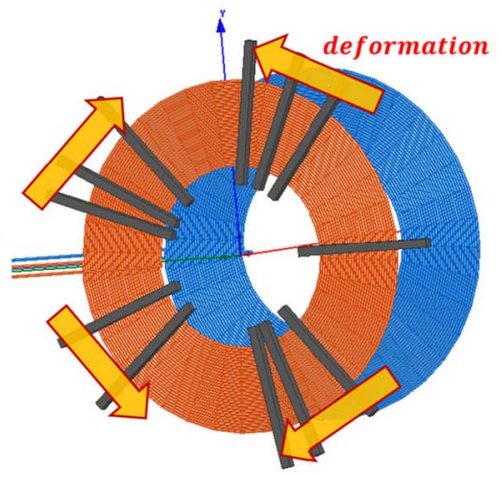

(c)

Fig. 12. Placement of the ferrite bar. (a) Initial position. (b) Moderate movement. (c) Significant movement.

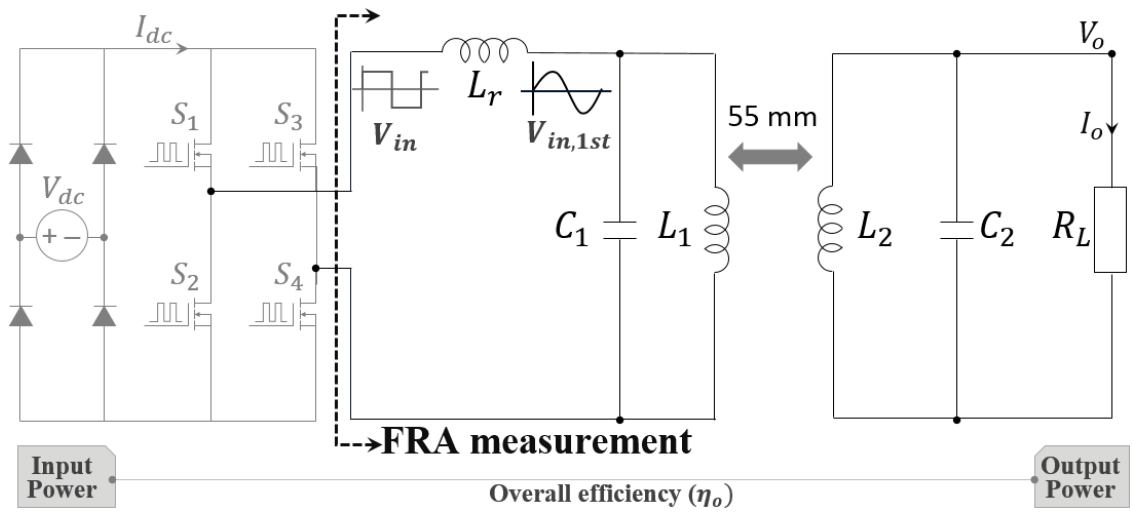

Fig. 13. Efficiency measurement of the WPT system.

TABLE V

OVERALL EFFICIENCY OF THE DEVELOPED PROTOTYPE.

\begin{tabular}{|c|c|c|c|c|c|c|c|}
\hline $\begin{array}{c}V_{d c} \\
{[\mathrm{~V}]}\end{array}$ & $\begin{array}{c}I_{d c} \\
{[\mathrm{~A}]}\end{array}$ & $\begin{array}{c}P_{d c} \\
{[\mathrm{~W}]}\end{array}$ & $\begin{array}{c}V_{o} \\
{[\mathrm{~V}]}\end{array}$ & $\begin{array}{c}I_{o} \\
{[\mathrm{~A}]}\end{array}$ & $\begin{array}{c}\theta_{o} \\
{\left[{ }^{\circ}\right]}\end{array}$ & $\begin{array}{c}P_{o} \\
{[\mathrm{~W}]}\end{array}$ & $\begin{array}{c}\eta_{o} \\
{[\%]}\end{array}$ \\
\hline 30.0 & 0.19 & 5.71 & 16.32 & 0.324 & 22.2 & 4.90 & 85.75 \\
\hline
\end{tabular}

A brief comparison of various compensation topologies is presented in Table VI. As each compensation topology has advantage and disadvantage, it is essential to carefully select the optimal design parameters for better performance of the
WPT system. For instance, the SS topology is widely applicable for the high-power applications such as the high-speed train, EV battery charging because the compensating circuit is independent of the load resistance and the air gap [12], [18], [19], [47] and the additional series inductor to provide a sinusoidal current to the parallel resonance circuit is unnecessary [38]. However, the SS topology requires a high-current rating power supply that may result in a malfunction when the magnetic coupling between the coils does not exist, e.g., $k_{12}=0$ [54]. For this reason, the PP topology with an additional series inductor and other supplemented compensation topologies are also adopted. The SP system is applicable for charging a battery of a medical implement device as it supplies 


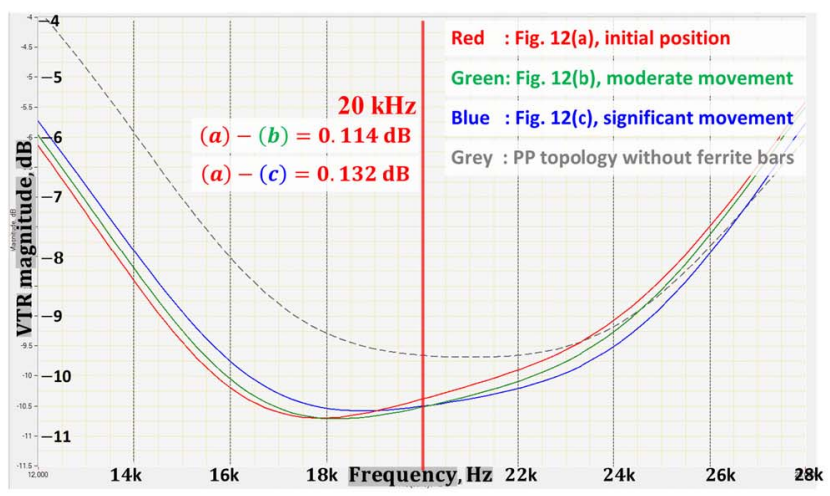

(a)

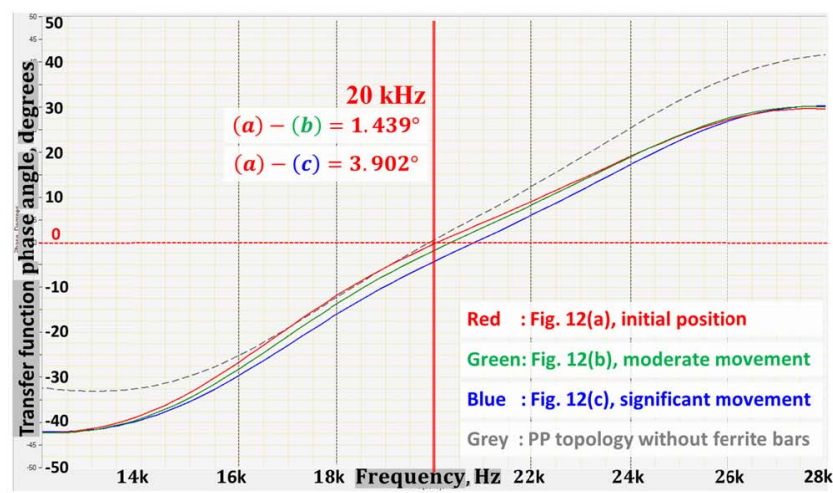

(b)

Fig. 14. FRA plots at the air gap of $55 \mathrm{~mm}$ for various placements of the ferrite rods (a) VTR and (b) phase angle $\delta^{\circ}$ of the transfer function $H_{(j \omega)}$.

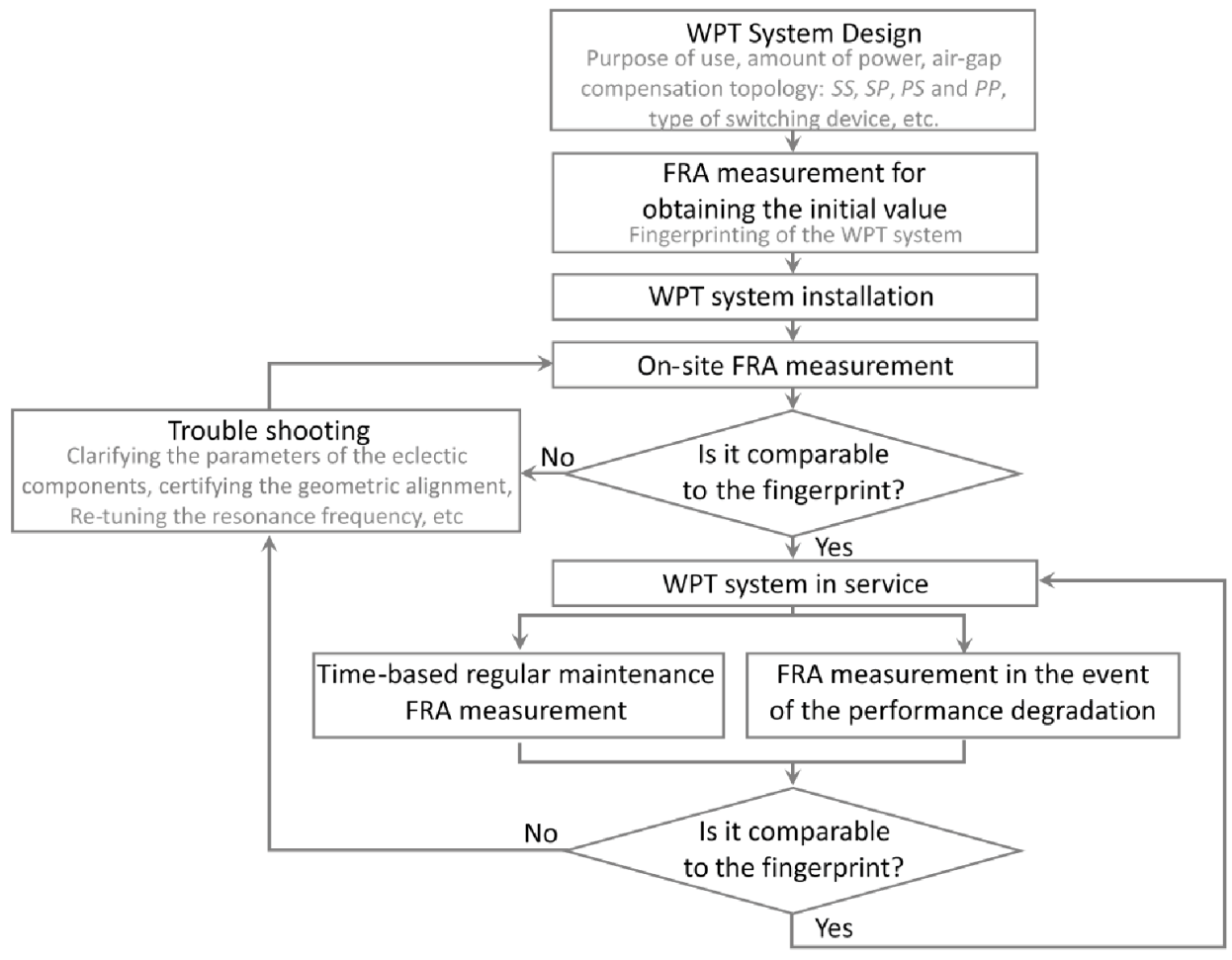

Fig. 15. Flowchart of FRA application on WPT system.

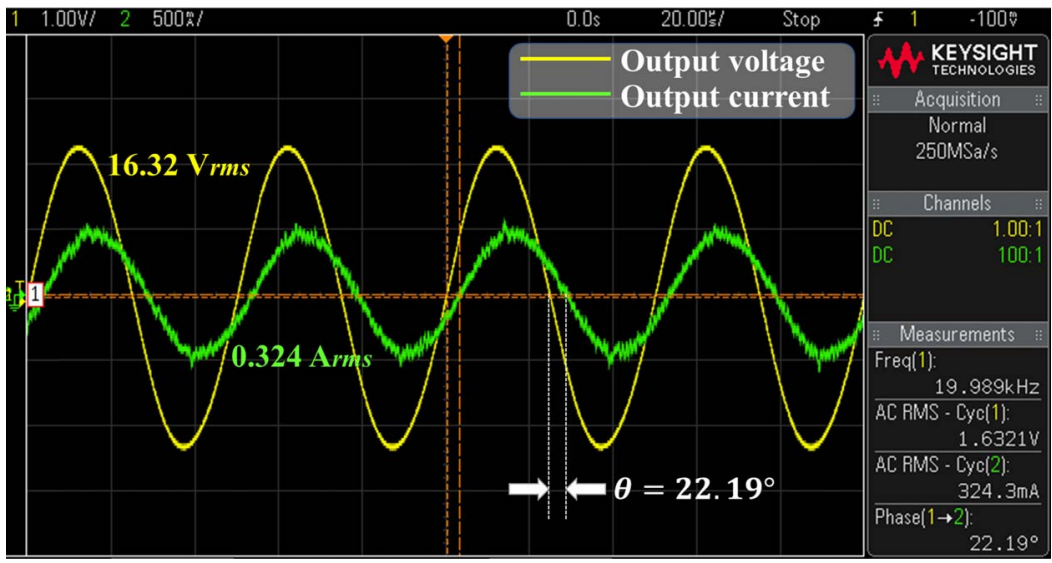

Fig. 16. Voltage and current waveforms on $R_{L}$.

a constant voltage regardless of the load resistance [1], [55]. Hence, the correct compensating topology should be selected by considering the purpose of use, the capacity of transfer energy, type of converter, and safety to accomplish a maximum efficiency or a maximum level of the power transfer. 
TABLE VI

COMPARISON OF COMPENSATION TOPOLOGY

\begin{tabular}{|c|c|c|c|c|c|}
\hline Topology & $\begin{array}{c}\text { Power supply } \\
\text { requirement }\end{array}$ & $\begin{array}{c}\text { Additional } \\
\text { series inductor }\end{array}$ & $\begin{array}{c}\text { Stability } \\
\text { when } k_{12}=0\end{array}$ & Compensating capacitor $C_{1}$ & $\begin{array}{c}\text { Input impedance value } \\
\text { when the distance increases }\end{array}$ \\
\hline$S S$ & Low voltage rating & Not required & Unstable & Independent from $k_{12}$ and load & Decrease \\
\hline$S P$ & Low voltage rating & Not required & Unstable & Function of $k_{12}$ or load & Decrease \\
\hline$P S$ & Low current rating & Required & Stable & Function of $k_{12}$ and load & Increase \\
\hline$P P$ & Low current rating & Required & Stable & Function of $k_{12}$ and load & Increase \\
\hline
\end{tabular}

\section{CONCLUSION}

In this paper, FRA is employed to assess various compensating topologies of the inductively coupled WPT system. The amplitude and the phase angle of the input impedance along with the VTR in the four available topologies (SS, SP, PS, and PP) of the WPT system are examined at various transfer distances $(10,55$, and $200 \mathrm{~mm})$. The key conclusions drawn from the FRA measurements can be summarized as follows.

1) At air-gap distances of 10 and $55 \mathrm{~mm}$, the amplitude and phase angle can be precisely measured. Therefore, the resonance frequency can be precisely tuned.

2) As the coupling coefficient is very weak at higher air-gap distance $(200 \mathrm{~mm})$, a rapid change of the impedance characteristic takes place near the resonance frequency leading to a significant disagreement between calculated and measured resonance frequency.

3) When the transfer distance increases, the width of the VTR traces in the SS and SP becomes narrow at the vicinity of the resonance frequency. The PS and PP topologies exhibit the opposite trend compared with the SS and SP topologies.

4) Experimental results show that the PP compensation-based WPT system with ferrite rods and series inductance in the transmitter has an overall efficiency of $85.75 \%$.

5) The FRA measurements can detect any displacement in the additional ferrite bars on the winding, and the geometric change of the WPT components.

6) When the initial FRA measurement is obtained as a fingerprint, the FRA diagnosis can facilitate cost-effective condition-based maintenance scheme and retuning system parameters to maintain high operational performance.

\section{APPENDIX}

\section{DERIVATIONS OF THE INPUT IMPEDANCE}

As depicted in Figs. 2 and 3, the impedance on the Rx side and the mutual inductance can be simplified as a reflected equivalent impedance $\dot{Z}_{\mathrm{eq}}$ and the impedance with the series compensation on the Rx side can be expressed as

$$
\begin{aligned}
& \operatorname{Re}\left(\dot{Z}_{\text {eq,se }}\right)=\left|R_{\text {eq }, \mathrm{se}}\right|=\frac{\omega^{2} M_{12}^{2}}{R_{\mathrm{L}}} \cdot \frac{1}{1+\gamma^{2}} \\
& \operatorname{Im}\left(\dot{Z}_{\text {eq,se }}\right)=\left|X_{\text {eq,se }}\right|=\omega L_{1}+\frac{\omega^{2} M_{12}^{2}}{R_{\mathrm{L}}} \frac{\gamma}{(1+\gamma)} .
\end{aligned}
$$

The normalized constant of the reactive component $\gamma$ is equivalent to $Q_{2}\left(\omega / \omega_{o}-\omega_{o} / \omega\right)$. When the operating frequency reaches the resonance frequency, $\gamma$ vanishes. The operating and resonance angular frequencies are denoted by $\omega$ and $\omega_{o}$, respectively. In addition, the load quality factor $Q_{2}$ is the ratio between the load resistance and the reactance value at the Rx side. For parallel compensation topology on the Rx side, the equivalent impedance is

$$
\begin{aligned}
& \operatorname{Re}\left(\dot{Z}_{\text {eq,pa }}\right) \\
& =\left|R_{\text {eq,pa }}\right| \\
& =\frac{\omega^{2} L_{1} L_{2}}{R_{\mathrm{L}}} \frac{\left\{\tau\left(k_{12}^{2}-1\right)+\frac{\omega^{2}}{\omega_{o}^{2}}\left(k_{12}^{2}-1+\frac{\omega_{o}^{2}}{\omega^{2}}\right)\right\}}{\tau^{2}+\frac{\omega^{2} L_{2}^{2}}{R_{\mathrm{L}}^{2}}} \\
& \begin{aligned}
\operatorname{Im}\left(\dot{Z}_{\text {eq,pa }}\right) \\
=\left|X_{\text {eq,pa }}\right|
\end{aligned} \\
& =\frac{\omega L_{1}\left\{\frac{\omega^{2}}{\omega_{o}^{2}} \tau\left(k_{12}^{2}-1+\frac{\omega_{o}^{2}}{\omega^{2}}\right)-\frac{\omega^{2} L_{2}^{2}}{R_{\mathrm{L}}^{2}}\left(k_{12}^{2}-1\right)\right\}}{\tau^{2}+\frac{\omega^{2} L_{2}^{2}}{R_{\mathrm{L}}^{2}}}
\end{aligned}
$$

where $\tau$ is the nominalization factor of the resonance frequency and is determined from $\tau=1-\left(\omega^{2} / \omega_{o}^{2}\right)$.

When the compensation capacitor $C_{1}$ is connected to $\dot{Z}_{\text {eq, se }}$ or $\dot{Z}_{\text {eq,pa }}$ in series for the SS or SP topology as shown in Fig. 3(a), the total input impedance $\dot{Z}_{\text {in,SS }}$ and $\dot{Z}_{\text {in,SP }}$ can be calculated by adding the capacitive reactance value based on $C_{1}$ to (12) and (14). On the other hand, to accomplish the PS or PP topology as depicted in Fig. 3(b), the compensating reactance influences the resistive and reactive components of the input impedance. The input impedance in the PS and PP topologies is expressed as

$$
\begin{aligned}
& \dot{Z}_{\mathrm{in}, \mathrm{PS}}=\frac{1}{j \omega C_{1}} / /\left(R_{\mathrm{eq}, \mathrm{Se}}+j X_{\mathrm{eq}, \mathrm{Se}}\right) \\
& \dot{Z}_{\mathrm{in}, \mathrm{PP}}=\frac{1}{j \omega C_{1}} / /\left(R_{\mathrm{eq}, \mathrm{Pa}}+j X_{\mathrm{eq}, \mathrm{Pa}}\right)
\end{aligned}
$$

If the WPT circuit is correctly in the resonance condition, only resistive parts exist as expressed in (1)-(4). However, if the nominalized factor $\gamma$ or $\tau$ is not zero, a residual value of the imaginary component will exist and it also affects to the resistive part of the equivalent impedance as shown in (11)-(14). If not compensated, this residual imaginary component results in a poor performance of the WPT system and a large capacity power supply must be used. 


\section{REFERENCES}

[1] S. Stoecklin, A. Yousaf, T. Volk, and L. Reindl, "Efficient wireless powering of biomedical sensor systems for multichannel brain implants," IEEE Trans. Instrum. Meas., vol. 65, no. 4, pp. 754-764, Apr. 2016.

[2] V. J. Brusamarello, Y. B. Blauth, R. de Azambuja, I. Müller, and F. R. de Sousa, "Power transfer with an inductive link and wireless tuning," IEEE Trans. Instrum. Meas., vol. 62, no. 5, pp. 924-931, May 2013.

[3] S. Y. Choi, B. W. Gu, S. Y. Jeong, and C. T. Rim, "Advances in wireless power transfer systems for roadway-powered electric vehicles," IEEE J. Emerg. Sel. Topics Power Electron., vol. 3, no. 1, pp. 18-36, Mar. 2015.

[4] J. Dai, S. Hagen, D. C. Ludois, and I. P. Brown, "Synchronous generator brushless field excitation and voltage regulation via capacitive coupling through journal bearings," IEEE Trans. Ind. Appl., vol. 53, no. 4, pp. 3317-3326, Jul. 2017.

[5] Z. Bi, T. Kan, C. C. Mi, Y. Zhang, Z. Zhao, and G. A. Keoleian, "A review of wireless power transfer for electric vehicles: Prospects to enhance sustainable mobility," Appl. Energy, vol. 179, pp. 413-425, Oct. 2016.

[6] W. Lumpkins, "Nikola Tesla's dream realized: Wireless power energy harvesting," IEEE Consum. Electron. Mag., vol. 3, no. 1, pp. 39-42, Jan. 2014.

[7] A. S. Marincic, "Nikola tesla and the wireless transmission of energy," IEEE Trans. Power App. Syst., vol. PAS-101, no. 10, pp. 4064-4068, Oct. 1982.

[8] G. R. M. Garratt, The Early History of Radio: From Faraday to Marconi (IET History of Technology Series 20). London, U.K.: IET, 1994.

[9] A. W. Green and J. T. Boys, "10 kHz inductively coupled power transferconcept and control," in Proc. 5th Int. Conf. Power Electron. VariableSpeed Drives, Oct. 1994, pp. 694-699.

[10] A. Kurs, A. Karalis, R. Moffatt, J. D. Joannopoulos, P. Fisher, and M. Soljačić, "Wireless power transfer via strongly coupled magnetic resonances," Science, vol. 317, no. 5834, pp. 83-86, Jul. 2007.

[11] C. Park, S. Lee, G.-H. Cho, and C. T. Rim, "Innovative 5-m-off-distance inductive power transfer systems with optimally shaped dipole coils," IEEE Trans. Power Electron., vol. 30, no. 2, pp. 817-827, Feb. 2015.

[12] Z. Li, K. Song, G. Wei, J. Jiang, and C. Zhu, "A 3-kW wireless power transfer system for sightseeing car supercapacitor charge," IEEE Trans. Power Electron., vol. 32, no. 5, pp. 3301-3316, May 2016.

[13] J. Dai and D. C. Ludois, "A survey of wireless power transfer and a critical comparison of inductive and capacitive coupling for small gap applications," IEEE Trans. Power Electron., vol. 30, no. 11, pp. 6017-6029, Nov. 2015.

[14] S. Y. R. Hui, W. Zhong, and C. K. Lee, "A critical review of recent progress in mid-range wireless power transfer," IEEE Trans. Power Electron., vol. 29, no. 9, pp. 4500-4511, Sep. 2014.

[15] X. Lu, P. Wang, D. Niyato, D. I. Kim, and Z. Han, "Wireless charging technologies: Fundamentals, standards, and network applications," IEEE Commun. Surveys Tuts., vol. 18, no. 2, pp. 1413-1452, 2nd Quart., 2016.

[16] S. Y. R. Hui, "Magnetic resonance for wireless power transfer [a look back]," IEEE Power Electron. Mag., vol. 3, no. 1, pp. 14-31, Mar. 2016.

[17] G. A. Covic and J. T. Boys, "Modern trends in inductive power transfer for transportation applications," IEEE Trans. Emerg. Sel. Topics Power Electron., vol. 1, no. 1, pp. 28-41, Mar. 2013.

[18] G. Guidi, J. A. Suul, F. Jenset, and I. Sorfonn, "Wireless charging for ships: High-power inductive charging for battery electric and plugin hybrid Vessels," IEEE Electrific. Mag., vol. 5, no. 3, pp. 22-32, Sep. 2017.

[19] J. H. Kim et al., "Development of 1-MW inductive power transfer system for a high-speed train," IEEE Trans. Ind. Electron., vol. 62, no. 10, pp. 6242-6250, Oct. 2015.

[20] P. T. M. Vaessen and E. Hanique, "A new frequency response analysis method for power transformers," IEEE Trans. Power Del., vol. 7, no. 1, pp. 384-391, Jan. 1992.

[21] N. Hashemnia, A. Abu-Siada, and S. Islam, "Improved power transformer winding fault detection using FRA diagnostics-Part 1: Axial displacement simulation," IEEE Trans. Dielectr. Elect. Insul., vol. 22, no. 1, pp. 556-563, Feb. 2015.

[22] N. Hashemnia, A. Abu-Siada, and S. Islam, "Improved power transformer winding fault detection using FRA diagnostics-Part 2: Radial deformation simulation," IEEE Trans. Dielectr. Elect. Insul., vol. 22, no. 1, pp. 564-570, Feb. 2015.

[23] H. Akcay, S. M. Islam, and B. Ninness, "Subspace-based identification of power transformer models from frequency response data," IEEE Trans. Instrum. Meas., vol. 48, no. 3, pp. 700-704, Jun. 1999.
[24] M. A. Abou-Khousa, M. A. Baumgartner, S. Kharkovsky, and R. Zoughi, "Novel and simple high-frequency single-port vector network analyzer," IEEE Trans. Instrum. Meas., vol. 59, no. 3, pp. 534-542, Mar. 2010.

[25] A. Holdyk, B. Gustavsen, I. Arana, and J. Holboell, "Wideband modeling of power transformers using commercial sFRA equipment," IEEE Trans. Power Del., vol. 29, no. 3, pp. 1446-1453, Jun. 2014

[26] D. Kim, A. Abu-Siada, and A. Sutinjo, "State-of-the-art literature review of WPT: Current limitations and solutions on IPT," Electr. Power Syst. Res., vol. 154, pp. 493-502, Jan. 2018.

[27] D. Kim, A. Abu-Siada, and A. Sutinjo, "A novel application of frequency response analysis for wireless power transfer system," in Proc. Australas. Univ. Power Eng. Conf. (AUPEC), Nov. 2017, pp. 1-6.

[28] C.-S. Wang, G. A. Covic, and O. H. Stielau, "Power transfer capability and bifurcation phenomena of loosely coupled inductive power transfer systems," IEEE Trans. Ind. Electron., vol. 51, no. 1, pp. 148-157, Feb. 2004.

[29] H. Hong, D. Yang, and S. Won, "The analysis for selecting compensating capacitances of two-coil resonant wireless power transfer system," in Proc. IEEE Int. Conf. Energy Internet (ICEI), Apr. 2017, pp. 220-225.

[30] S. C. Tang, S. Y. R. Hui, and H. S.-H. Chung, "Coreless planar printed-circuit-board (PCB) transformers-a fundamental concept for signal and energy transfer," IEEE Trans. Power Electron., vol. 15, no. 5, pp. 931-941, Sep. 2000.

[31] D. Kim, J. Kim, and Y.-J. Park, "Optimization and design of small circular coils in a magnetically coupled wireless power transfer system in the megahertz frequency," IEEE Trans. Microw. Theory Techn., vol. 64, no. 8, pp. 2652-2663, Aug. 2016.

[32] M. Borage, K. V. Nagesh, M. S. Bhatia, and S. Tiwari, "Design of LCL-T resonant converter including the effect of transformer winding capacitance," IEEE Trans. Ind. Electron., vol. 56, no. 5, pp. 1420-1427, May 2009.

[33] C. Carretero, "Coupling power losses in inductive power transfer systems with Litz-wire coils," IEEE Trans. Ind. Electron., vol. 64, no. 6, pp. 4474-4482, Jun. 2017.

[34] Q. Deng et al., "Frequency-dependent resistance of Litz-wire square solenoid coils and quality factor optimization for wireless power transfer," IEEE Trans. Ind. Electron., vol. 63, no. 5, pp. 2825-2837, May 2016.

[35] I.-S. Jeong, B.-I. Jung, D.-S. You, and H.-S. Choi, "Analysis of $S$-parameters in magnetic resonance WPT using superconducting coils," IEEE Trans. Appl. Supercond., vol. 26, no. 3, Apr. 2016, Art. no. 0501004.

[36] NEW Technologies. Round Litz-Wire Data Table. Accessed: Aug. 6, 2018. [Online]. Available: http://www.litzwire.com/nepdfs/Round_Litz_Catalog.pdf

[37] IEEE Guide for the Application and Interpretation of Frequency Response Analysis for Oil-Immersed Transformers, IEEE Standard C57.149-2012, 2013, pp. 1-72.

[38] J. Hou, Q. Chen, S.-C. Wong, C. K. Tse, and X. Ruan, "Analysis and control of series/series-parallel compensated resonant converter for contactless power transfer," IEEE J. Emerg. Sel. Topics Power Electron., vol. 3, no. 1, pp. 124-136, Mar. 2015.

[39] C.-S. Wang, G. A. Covic, and O. H. Stielau, "Investigating an LCL load resonant inverter for inductive power transfer applications," IEEE Trans. Power Electron., vol. 19, no. 4, pp. 995-1002, Jul. 2004.

[40] N. A. Keeling, G. A. Covic, and J. T. Boys, "A unity-power-factor IPT pickup for high-power applications," IEEE Trans. Ind. Electron., vol. 57, no. 2, pp. 744-751, Feb. 2010.

[41] S. D. Barman, A. W. Reza, N. Kumar, M. E. Karim, and A. B. Munir, "Wireless powering by magnetic resonant coupling: Recent trends in wireless power transfer system and its applications," Renew. Sustain. Energy Rev., vol. 51, pp. 1525-1552, Nov. 2015.

[42] H. Ishida and H. Furukawa, "Wireless power transmission through concrete using circuits resonating at utility frequency of $60 \mathrm{~Hz}$," IEEE Trans. Power Electron., vol. 30, no. 3, pp. 1220-1229, Mar. 2015.

[43] S. A. Ryder, "Diagnosing transformer faults using frequency response analysis," IEEE Elect. Insul. Mag., vol. 19, no. 2, pp. 16-22, Mar. 2003.

[44] H. M. Hashemian, "State-of-the-art predictive maintenance techniques," IEEE Trans. Instrum. Meas., vol. 60, no. 1, pp. 226-236, Jan. 2011.

[45] Y. Su, C. Tang, S. Wu, and Y. Sun, "Research of LCL resonant inverter in wireless power transfer system," in Proc. Int. Conf. Power Syst. Technol. Oct. 2006, pp. 1-6.

[46] C. Jiang, K. T. Chau, C. Liu, and C. H. T. Lee, "An overview of resonant circuits for wireless power transfer," Energies, vol. 10, no. 7, pp. 894-1-894-20, Jun. 2017. 
[47] Z. Huang, S. C. Wong, and C. K. Tse, "Design of a single-stage inductive-power-transfer converter for efficient EV battery charging," IEEE Trans. Veh. Technol., vol. 66, no. 7, pp. 5808-5821, Jul. 2017.

[48] Y. Yao, Y. Wang, X. Liu, F. Lin, and D. Xu, "A novel parameter tuning method for a double-sided $L C L$ compensated WPT system with better comprehensive performance," IEEE Trans. Power Electron., vol. 33, no. 10 , pp. $8525-8536$, Oct. 2018.

[49] S. Samanta, A. K. Rathore, and S. K. Sahoo, "Current-fed full-bridge and half-bridge topologies with CCL transmitter and LC receiver tanks for wireless inductive power transfer application," in Proc. IEEE Region 10 Conf. (TENCON), Nov. 2016, pp. 756-761.

[50] H. Hao, G. A. Covic, and J. T. Boys, "A parallel topology for inductive power transfer power supplies," IEEE Trans. Power Electron., vol. 29, no. 3, pp. 1140-1151, May 2014.

[51] S. Cheon, Y.-H. Kim, S.-Y. Kang, M. L. Lee, J.-M. Lee, and T. Zyung, "Circuit-model-based analysis of a wireless energy-transfer system via coupled magnetic resonances," IEEE Trans. Ind. Electron., vol. 58, no. 7 , pp. 2906-2914, Jul. 2011.

[52] H. Zhang, F. Lu, H. Hofmann, W. Liu, and C. C. Mi, "A sixplate capacitive coupler to reduce electric field emission in large airgap capacitive power transfer," IEEE Trans. Power Electron., vol. 33, no. 1, pp. 665-675, Jan. 2018

[53] D. Ahn and S. Hong, "A study on magnetic field repeater in wireless power transfer," IEEE Trans. Ind. Electron., vol. 60, no. 1, pp. 360-371, Jan. 2013.

[54] Y. H. Sohn, B. H. Choi, E. S. Lee, G. C. Lim, G. H. Cho, and C. T. Rim, "General unified analyses of two-capacitor inductive power transfer systems: Equivalence of current-source SS and SP compensations," IEEE Trans. Power Electron., vol. 30, no. 11, pp. 6030-6045, Nov. 2015.

[55] M. Saad, A. H. Mahammad, A. S. Salina, and H. Aini, "Analysis and optimization of spiral circular inductive coupling link for bio-implanted applications on air and within human tissue," Sensors, vol. 14, no. 7, pp. 11522-11541, Jun. 2014.

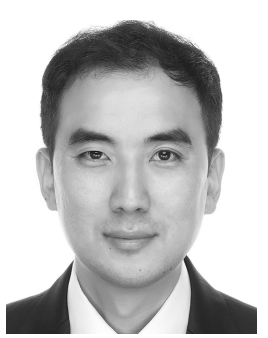

Dowon Kim received the B.Sc. and M.Sc. degrees in electrical engineering from the Seoul National University of Science and Technology, Seoul, South Korea, in 2003 and 2009, respectively. He is currently pursuing the Ph.D. degree with Curtin University, Bentley, WA, Australia.

From 1998 to 2011, he was a Transmission and Substation Engineer and an Engineering Lecturer with Korea Electric Power Corporation, Seoul. He was a Senior Testing and Commissioning Engineer with Global Testing Services, Canning Vale, WA, Australia until 2016. His current research interests include wireless power transfer system, frequency response, high-voltage condition monitoring, and power system protection.

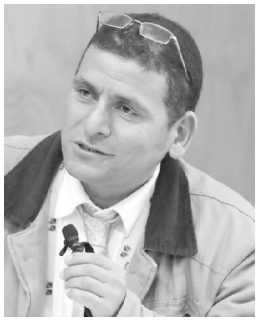

A. Abu-Siada (M'07-SM'12) received the B.Sc. and M.Sc. degrees in electrical engineering from Ain Shams University, Cairo, Egypt, in 1998, and the $\mathrm{Ph} . \mathrm{D}$. degree in electrical engineering from Curtin University, Bentley, WA, Australia, in 2004.

$\mathrm{He}$ is currently an Associate Professor with the Department of Electrical and Computer Engineering, Curtin University. His current research interests include power system stability, condition monitoring, power electronics, and power quality.

Dr. Abu-Siada is an Editor-in-Chief of the International Journal Electrical and Electronic Engineering, a regular reviewer for various IEEE Transactions, and a Vice-Chair of the IEEE Computation Intelligence Society, WA Chapter.

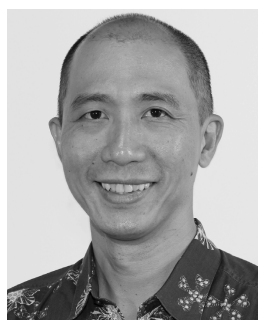

Adrian T. Sutinjo (SM'15) received the B.S.E.E. degree from Iowa State University, Ames, IA, USA, in 1995, the M.S.E.E. degree from the Missouri University of Science and Technology, Rolla, MO, USA, in 1997, and the Ph.D. degree in electrical engineering from the University of Calgary, Calgary, AB, Canada, in 2009.

From 1997 to 2004, he was an RF Engineer with Motorola, Chicago, IL, USA, and with Murandi Communications Ltd., Calgary, AB, Canada. He is currently a Senior Lecturer with the School of Electrical Engineering, Computing and Mathematics, Curtin University, Perth, WA, Australia, where he has been with the International Centre for Radio Astronomy Research since 2012. His current research interests include antennas, RF and microwave engineering, electromagnetics, and radio astronomy engineering. 